\title{
MOTHER'S EDUCATION AND ANTENATAL CARE VISITS IN NEPAL
}

\author{
Bidhya Shrestha*
}

\begin{abstract}
The proper use of antenatal care (ANC) visit is the first step to prevent both mother and child health. This is also one of the key components to achieve the Sustainable Development Goals by 2030. The study is an attempt to assess the relation between mother's education and utilization of ANC services in Nepal. It is completely based on data of national representative 2016 Nepal Demographic and Health Survey that covered 2,746 currently married women, aged 15-49 years who had at least one child in the last three years preceding the survey. Logistic regression was used to analyze the effect of education on the utilization of ANC services. Results showed that a higher level of maternal education increased the chance of utilizing ANC services than those with little or no education. The importance of maternal education continued even when other socioeconomic factors are taken into account. This indicates that mother's education contribute to increase the use of proper ANC services.
\end{abstract}

Keywords: Maternal education, antenatal care, antenatal visit, and NDHS.

\section{INTRODUCTION}

Women and men share many similar health challenges. In some aspect the health of women deserves particular attention. Women generally live longer than men because of both biological and behavioral advantages. Moreover, women's longer lives are not necessarily healthy lives. There are conditions that only women experience i.e., pregnancy and childbirth. These are not diseases, but biological and social processes that carry health risks and require health care (WHO, 2009). Thus care during pregnancy i.e. antenatal care (ANC) is important for the survival and well-being of both mother and her child. It is the first step to prevent not only the mother but also the child's health (Bloom, Lippeveld, \& Wypij, 1999). ANC offers pregnant women an entry point to the health care system, providing appropriate screening intervention and treatment throughout pregnancy, and encouraging women to seek a skilled birth attendant for their delivery (Zahr \& Lidia, 2003). Because the principles of ANC for women with uncomplicated pregnancies

* Ms. Shrestha is a Lecturer, Central Department of Population Studies, Kirtipur, TU. 
are to provide advice, education, reassurance and support; to address and treat the minor problems of pregnancy; and to provide effective screening during the pregnancy. Chan \& Kean (2004) stated that the initial visit is the most important visit for all pregnant women. Moreover, a single antenatal visit also does not give information about the completeness and components of the care provided. World Health Organization (WHO) recommends that all women should initiate their first antenatal care in the first trimester of pregnancy and should have at least four antenatal visits to avoid the health risk during pregnancy (WHO, 2016).

According to WHO (2016) recommendation, ANC services have to be provided within four visits for women having normal progress on her pregnancy. The main purpose of the four visits is to identify the complication if any and treating them in addition to addressing behavioral factors. Within this framework government of Nepal has also made a provision of incentive for 4 ANC visits by providing cash payment of NRs. 400. The amount is given to women who made complete four ANC visits at the $4^{\text {th }}, 6^{\text {th }}, 8^{\text {th }}$ and $9^{\text {th }}$ months of pregnancy to have a safe delivery from skilled health personnel. Despite this provision still there are many cases that do not have adequate number of visits and the care may not be provided by skilled birth attendants. The effectiveness of ANC mostly depends on the continuation of the receiving care from first trimester to throughout pregnancy.

It is generally acknowledged that the health status of people is influenced by variety of factors which are outside the domain of public health system (Preda \& Vogit, 2015). A number of factors like cultural barriers, low literacy and economic status, place of residence affect a woman's likelihood of attending ANC, contributing to enormous disparities in accessibility and utilization even if they are provided high quality services (WHO; UNICEF, 2003). Ndidi and Oserement (2001) stated that not knowing the right gestation age at which to start the first ANC visit was most common reason for late attendance.

Utilization of ANC differences exist within and among the countries. The proportion of women who attend ANC is low especially in developing countries which account for poorer maternal health indices compared to the developed countries. One study found that the percentage of women who attended at least 4 ANC visits ranged from 18 percent in Guatemala to 81 percent in Nicaragua (Maternal Health Task Force, n.d.). In Nepal, it is about 69 percent of women who attended 4 or more ANC visits in the last 5 years preceding the survey (Ministry of Health, ERA, \& ICF, 2017). Still, there are 30 percent women left behind. 
Different factors have been found to be related with the use of antenatal health care visit. However, to increase ANC visit, mothers and their families should know the importance of ANC visit which is possible only through education. Women's health seeking behavior is highly influenced by their educational status. There is positive relationship between mother's education and utilization of $\mathrm{MCH}$ services. It further shows that preventive health care services are used to a greater extent by mothers with higher education than there less educated counterparts (Govindasamy \& Ramesh, 1997). More educated women are more likely to receive prenatal care, to have been immunized with tetanus toxoid during pregnancy, and to have their deliveries attended by trained personnel (Hobcarft, 1993). According to worldwide survey study, maternal mortality rate tend to be higher in countries where female literacy rate is lower than male counterparts (McAlister \& Baskett, 2006). The study also shows women's education as a powerful indicator of maternal mortality and women's education can provide the knowledge to demand and seek proper health care.

As Caldwell (1979) stated that educated women are considered to have greater awareness of the existence of maternal health care services and benefits in using such services. They are likely to enjoy more autonomy within and outside the household and the skill acquired from schooling enable women to communicate with the health professionals and demand health care services. Educated mothers are also likely to have improved knowledge and information on modern medical treatment and have greater capacity to recognize specific illness. As the health care seeking behavior is a complex phenomenon which can also be influenced by socio-cultural settings, it needs a contextual thorough investigation. Thus, the aim of this study is to assess the relationship between mother's education and utilization of ANC services in Nepal.

\section{OBJECTIVE}

The main objective of this study is to analyze the effect of maternal education on antenatal visits. This information will help to implement the program for target population to improve the focused ANC visit and improve maternal health indices in the state.

\section{METHODOLOGY}

This study is based on secondary data using nationally representative sample survey, NDHS 2016. The main aim of this study is to identify the influence of maternal education on ANC visit during pregnancy in Nepal. In the analysis the study is considered only currently married women aged 
15-49 years who had at least one child in the last three years preceding the survey. If a woman had more than one child, information about the most recent live birth is considered. The study population for this analysis is 2,746. The association between antenatal care (ANC) visit and women education level, socioeconomic and demographic characteristics related to them are analyzed in this study.

The main independent (predictor) variable- mother's educational level is grouped into four categories: no education, primary, secondary and higher. Besides this, other some important demographic and socioeconomic variables are considered as controlled variables for the study, i.e. maternal age, place of residence, province, wealth index, occupation and media exposure.In this study ANC visit is a dependent variable (outcome variables) which is dichotomized as 'proper use of ANC visit' for women who attend the 4 or more ANC visits and 'improper use of ANC visit' for the women who attend less than four or no antenatal care visits.

The analysis begins with descriptive statistics to understand the distribution of different independent variables in relation to outcome variable, that is current ANC practice and chi-square test is performed to see the significance of the associations. Significant outcomes are then analyzed using multiple logistic regressions to identify the independent effects of explanatory variables on the outcomes of interest. The crude and adjusted odd ratios together with their corresponding 95\% confidence intervals are computed and interpreted accordingly.

\section{RESULTS AND DISCUSSION}

Nearly 35 percent of mothers had completed secondary level education. About three in ten (29.7\%) mothers were illiterate. Data further shows that about 70 percent of mother had used proper ANC utilization for their most recent pregnancy. Nearly half of the mothers were in the age group 15-24 years. While talking about the place of residence and province about 54 percent were from urban areas and one fourth $(25.4 \%)$ of them were from province 2 respectively. Likewise, 40 percent of the mothers had exposure to television or radio. More than 40 percent of mothers were in the poor wealth quintile group. About 44 percent were engaged in agriculture self-employed/employee. Similary about 42 percent of the respondents were from poor household wealth (Table 1). 
Table 1: Percentage Distribution of Respondents According to Background Characteristics, 2016

\begin{tabular}{|c|c|c|}
\hline Background Characteristics & Percent & $\mathbf{N}$ \\
\hline \multicolumn{3}{|l|}{ Highest Education Level } \\
\hline No education & 29.7 & 814 \\
\hline Primary & 20.1 & 552 \\
\hline Secondary & 34.8 & 956 \\
\hline Higher & 15.5 & 425 \\
\hline \multicolumn{3}{|l|}{ ANC Visit } \\
\hline Improper used & 29.6 & 813 \\
\hline Proper used & 70.4 & 1933 \\
\hline \multicolumn{3}{|l|}{ Maternal Age } \\
\hline $15-24$ & 48.1 & 1321 \\
\hline $25-29$ & 36.5 & 1004 \\
\hline $30+$ & 15.3 & 421 \\
\hline \multicolumn{3}{|l|}{ Place of Residence } \\
\hline Rural & 45.6 & 1253 \\
\hline Urban & 54.4 & 1494 \\
\hline \multicolumn{3}{|l|}{ Province } \\
\hline Province 1 & 17.1 & 470 \\
\hline Province 2 & 25.4 & 696 \\
\hline Province 3 & 16.2 & 445 \\
\hline Province 4 & 8.4 & 232 \\
\hline Province 5 & 18.3 & 502 \\
\hline Province 6 & 6.4 & 177 \\
\hline Province 7 & 8.1 & 224 \\
\hline \multicolumn{3}{|l|}{ Media Exposure } \\
\hline Neither watch TV or listen radio & 22.7 & 622 \\
\hline Watch TV or listen radio & 39.9 & 1096 \\
\hline Watch TV and listen radio & 37.4 & 1028 \\
\hline \multicolumn{3}{|l|}{ Occupation } \\
\hline Not working & 43.6 & 1198 \\
\hline Agriculture self-employed/employee & 43.9 & 1205 \\
\hline Non agriculture & 12.5 & 344 \\
\hline \multicolumn{3}{|l|}{ Wealth Index } \\
\hline Poor & 42.3 & 1163 \\
\hline Middle & 21.9 & 601 \\
\hline Rich & 35.8 & 982 \\
\hline Total & 100.0 & 2746 \\
\hline
\end{tabular}

Source: Dataset of NDHS, 2016 
About 70 percent of mothers made required number of visits to health professional during pregnancy period. While talking about ANC visit by their education level, it varied by their education levels. Result shows that the percentage of receiving ANC increased with mother's education. For example about 52 percent of the mothers with no education made 4 or more ANC visits which is lowest in comparison to the mothers who have higher education level (52.4\% Vs 94.2\%). The chi-square test shows statistically significant $(\mathrm{p}<.001)$ in difference between different levels of mother's education and ANC (Table 2).

Likewise, more young mothers received proper ANC visits than older mothers $(71.8 \%$ Vs $65.3 \%)$. According to place of residence, rural mothers were less likely to made proper ANC visits than urban mothers. About 76 percent of women in urban areas reported receiving proper use of ANC visits compared with 64 percent in rural areas. Similarly, receiving proper ANC services was more common in all provincial level except provinces 2 and 6 . Only a little more than half of the mothers from province 2 and 6 received proper ANC visits in comparison with other provinces. About 82 percent of mothers from province 7 made proper use of ANC visits which is highest among the provincial level.

Media exposure is another factor that influences ANC visits. Data reveals that more mothers who had exposure to electronic media, i.e. television and radio, made 4 or more ANC visit than their counterparts (83.1\% Vs $51.0 \%)$. Further, it shows that 80 percent of mothers who were engaged in non-agriculture occupation were made required number of ANC visits, whereas, it was only about 67 percent for not working mothers. From the table it appeared that receiving antenatal care improves with household wealth. Mother from poor household had less antenatal visit than mothers from rich household $(63.8 \%$ Vs $79.9 \%)$. It shows that increased household economic status increases the use of recommended ANC visit. All independent variables were statistically significant at less than $1 \%$ level (Table 2). 
Table 2 : Percentage Distribution of Women Age 15-49 Who had a Live Birth in the 3 Years Preceding the Survey by Number of ANC Visit for Their Most Recent Birth According to Background Characteristics, 2016

\begin{tabular}{|c|c|c|c|c|}
\hline \multirow{2}{*}{$\begin{array}{l}\text { Background } \\
\text { Characteristics }\end{array}$} & \multicolumn{2}{|c|}{ ANC visit } & \multirow[b]{2}{*}{$\mathbf{N}$} & \multirow{2}{*}{$\begin{array}{l}\text { Chi-square } \\
\text { (p-value) }\end{array}$} \\
\hline & $\begin{array}{l}\text { Improper Use } \\
\text { of ANC Visit }\end{array}$ & $\begin{array}{l}\text { Proper Use } \\
\text { of ANC Visit }\end{array}$ & & \\
\hline \multicolumn{4}{|l|}{ Level of Education } & \multirow{5}{*}{$<0.001$} \\
\hline No education & 47.6 & 52.4 & 814 & \\
\hline Primary & 36.7 & 63.3 & 552 & \\
\hline Secondary & 20.8 & 79.2 & 956 & \\
\hline Higher & 5.8 & 94.2 & 425 & \\
\hline \multicolumn{4}{|l|}{ Maternal Age } & \multirow{4}{*}{$<0.001$} \\
\hline $15-24$ & 28.2 & 71.8 & 1321 & \\
\hline $25-29$ & 29.3 & 70.7 & 1004 & \\
\hline 30 and above & 34.7 & 65.3 & 421 & \\
\hline Place of Residence & & & & $<0.001$ \\
\hline Urban & 24.4 & 75.6 & 1494 & \\
\hline Rural & 35.8 & 64.2 & 1253 & \\
\hline \multicolumn{4}{|l|}{ Province } & \multirow{8}{*}{$<0.001$} \\
\hline Province 1 & 23.3 & 76.7 & 470 & \\
\hline Province 2 & 44.6 & 55.4 & 696 & \\
\hline Province 3 & 21.9 & 78.1 & 445 & \\
\hline Province 4 & 22.1 & 77.9 & 232 & \\
\hline Province 5 & 24.5 & 75.5 & 502 & \\
\hline Province 6 & 45.3 & 54.7 & 177 & \\
\hline Province 7 & 18.5 & 81.5 & 224 & \\
\hline \multicolumn{4}{|l|}{ Media Exposure } & \multirow{4}{*}{$<0.001$} \\
\hline $\begin{array}{l}\text { Neither watch TV or listen } \\
\text { radio }\end{array}$ & 49.0 & 51.0 & 622 & \\
\hline Watch TV or listen radio & 30.6 & 69.4 & 1096 & \\
\hline Watch TV and listen radio & 16.9 & 83.1 & 1028 & \\
\hline \multicolumn{4}{|c|}{\begin{tabular}{l|l} 
Occupation & \\
\end{tabular}} & \multirow{4}{*}{$<0.001$} \\
\hline Not working & 33.2 & 66.8 & 1198 & \\
\hline Agriculture self employed & 28.8 & 71.2 & 1205 & \\
\hline Non agriculture & 19.8 & 80.2 & 344 & \\
\hline \multicolumn{4}{|l|}{ Wealth Index } & \multirow{4}{*}{$<0.001$} \\
\hline Poor & 36.2 & 63.8 & 1163 & \\
\hline Middle & 32.4 & 67.6 & 601 & \\
\hline Rich & 20.1 & 79.9 & 982 & \\
\hline Total & 29.6 & 70.4 & 2746 & \\
\hline
\end{tabular}

Source: Dataset of NDHS, 2016 
Education is an indicator of both class and status, it is correlated with income and occupation and it is often used as a proxy for socioeconomic grouping (Yakubovich \& Barell, 1988). Some sociological theories conceptualize formal education as an experience that transforms women's attitudes and influences their adoption of 'modern' ideas. Researchers hypothesize that going to formal school changes a woman's attitudes about traditional gender roles, allowing her to achieve greater decision making autonomy within the household (Jejeebhoy S., 1995). Researcher also hypothesize that the content of formal education challenges traditional beliefs about sickness and health and promote ideologies that align with the use of modern health care (Caldwell, 1979). This study aims to identify the effect of maternal education on proper ANC visits. Logistic regression analysis on the antenatal care service utilization was employed to identify the effects of mother's education on proper use of antenatal care visit. There are two model one is crude and another is adjusted. In crude model univariate analysis was made to show the effect of each independent variable on ANC visits, whereas, all the demographic and socioeconomic variables are added in adjusted model. Odds ratio along with $\mathrm{p}$-value are shown in Table 3.

In crude model, result shows the highly significant association between maternal education and proper ANC visit. Odds ratio reported in Table 3 confirms that women with a higher education are more likely than their no educated peers to visit for ANC services $(\mathrm{OR}=14.86)$. The odd ratios revealed that mother's education could have impact on proper use of ANC visit. Result obtained from adjusted model also confirms that maternal education provides a significant association with proper use of ANC visits controlling some important demographic and socioeconomic variables. Result shows that mother with higher education are about 8 times $(\mathrm{OR}=7.901)$ more likely to made required ANC visit than mother with no education (Table 3). The result of this study shed light on the factor that could affect utilization of ANC visit i.e., increased educational status of mothers increased the likelihood of getting ANC visit which is consistent with the previous studies (Kabir, 2016) which supports the present study findings. And also support the Yakong, Rush, Bassett-Smith, Bottorff, \& Ronison, (2010) results that emphasis the women education to seek antenatal health care.

Likewise, the age of mother influence the use of ANC services. It is observed from the Table 3 that young mothers are likely to visit for antenatal care 1.06 times more than older women. Result shows that younger the mother is, the more likely she is to make ANC visit which is consistent with a study conducted by (Arthur 2012) on utilization of maternal healthcare services in Ghana that reveals antenatal care utilization reduced with respect 
to age increase of expectant mothers. On the contrary, studies from Klemetti, Gissler, Sainio, \& Hemminki, 2013) confirm that older women were more likely to use antenatal care services than their younger counterparts.

Table 3: Odd Ratio (OR) and 95 Percent Confidence Interval (CI) for Antenatal Visit to Currently Married Women Aged 15-49 by Education Level

\begin{tabular}{|c|c|c|}
\hline Variables & $\begin{array}{c}\text { Crude } \\
\text { OR( } 95.0 \% \text { CI })\end{array}$ & $\begin{array}{c}\text { Adjusted } \\
\text { OR( } 95.0 \% \text { CI })\end{array}$ \\
\hline \multicolumn{3}{|l|}{ Mother's Education } \\
\hline No education (Ref) & 1 & 1 \\
\hline Primary & $1.563(1.253-1.950)^{*}$ & $1.209(0.938-1.559)$ \\
\hline Secondary & $3.443(2.796-4.239)^{*}$ & $2.022(1.557-2.626)^{*}$ \\
\hline Higher & $\begin{array}{r}14.860(9.657- \\
22.867)^{*}\end{array}$ & $7.447(4.551-12.187)^{*}$ \\
\hline \multicolumn{3}{|l|}{ Maternal Age } \\
\hline $15-24$ (Ref) & 1 & 1 \\
\hline $25-29$ & $1.060(0.876-1.284)$ & $1.020(0.821-1.267)$ \\
\hline 30 and above & $0.878(0.683-1.129)$ & $1.020(0.765-1.359)$ \\
\hline \multicolumn{3}{|l|}{ Place of Residence } \\
\hline Urban(Ref) & 1 & 1 \\
\hline Rural & $0.582(0.489-0.693)^{*}$ & $0.845(0.697-1.025)$ \\
\hline \multicolumn{3}{|l|}{ Province } \\
\hline Province 1(Ref) & 1 & 1 \\
\hline Province 2 & $0.337(0.256-0.445)^{*}$ & $0.476(0.351-0.646)^{*}$ \\
\hline Province 3 & $1.065(0.763-1.487)$ & $0.816(0.571-1.165)$ \\
\hline Province 4 & $1.138(0.752-1.722)$ & $0.841(0.544-1.300)$ \\
\hline Province 5 & $0.902(0.657-1.238)$ & $0.856(0.612-1.196)$ \\
\hline Province 6 & $0.410(0.275-0.610)^{*}$ & $0.488(0.318-0.750)$ \\
\hline Province 7 & $1.251(0.818-1.912)$ & $1.302(0.834-2.032)$ \\
\hline \multicolumn{3}{|l|}{ Media Exposure } \\
\hline $\begin{array}{l}\text { Neither watch TV or listen } \\
\text { radio (Ref) }\end{array}$ & 1 & 1 \\
\hline Watch TV or listen radio & $2.069(1.671-2.562)^{*}$ & $1.341(1.062-1.692)$ \\
\hline Watch TV and listen radio & $4.309(3.398-5.456)^{*}$ & $1.870(1.424-2.456)^{*}$ \\
\hline \multicolumn{3}{|l|}{ Occupation } \\
\hline Not working(Ref) & 1 & 1 \\
\hline Agriculture self employed & $2.207(1.615-3.016)^{*}$ & $1.218(0.860-1.726)$ \\
\hline Non agriculture & $1.377(1.147-1.655)^{*}$ & $1.519(1.215-1.901)$ \\
\hline \multicolumn{3}{|l|}{ Wealth Index } \\
\hline Poor(Ref) & 1 & 1 \\
\hline Middle & $1.024(0.824-1.273)$ & $1.378(1.063-1.785)$ \\
\hline Rich & $2.000(1.626-2.461)^{*}$ & $1.703(1.311-2.213)^{*}$ \\
\hline
\end{tabular}

Note: Ref=reference group; $*$ Significant at $<001$, controlled variables: maternal age, place of residence, education, media, occupation and wealth index 
Moreover, mother from rural areas are about 16 percent $(\mathrm{OR}=0.845)$ less likely to use proper ANC visit compared to the urban women. The results showed that mother living in urban areas were more likely to seek recommended ANC visit as compared to their rural counterpart even after controlling the other variables. it support Pandy \& Singh (2015) argument that place of residence as strong indicators of ANC visits. Similalry, Provincial level data elucidates that mothers from province 7 are more likely to made proper ANC visit than other 6 provinces. Mothers from province 2 are 66 percent less likely $(\mathrm{OR}=0.337)$ to receive $\mathrm{ANC}$ visit than other provinces. Also, it can be observed that the odd of having proper ANC visits for the mothers who are exposed to media is higher $(\mathrm{OR}=1.870)$ compared to the mothers who are not exposed to both media and is a potential factor for proper ANC visits at $1 \%$ level of significance.

The variable mother's occupation is found insignificantly effect on proper ANC visit in adjusted model. Mothers who were engaged in nonagriculture are likely to visit 1.519 times more compared to women with no work. The difference between rich and poor wealth quintile are little high and the likelihood of getting ANC visits increased with improved wealth status. Result shows that household wealth still influences the ANC visit in Nepal even after the introduction of the provision of incentives.

\section{CONCLUSION}

The study examined the effect of education on antenatal visit in Nepal using the data from NDHS. The results pinpointed the importance of maternal education to have recommended ANC visit. Even though there are incentives for 4 ANC visits, sufficient utilization of ANC has not yet been achieved as varied demographic and socioeconomic factors. These factors still pose problem to some mothers in using the services. Thus more education is mandatory for pregnant women during ANC visit to address different aspect of pregnancy and its complication. Local (government) and development organization should work deliberately to address factor responsible for the low use of ANC services. This can be done through the various mediums of media and counselling during ANC visits. As this study also suggested the effect of media was more pronounced on antenatal visit. 


\section{REFERENCES}

Arthur, E. (2012). Wealth and antenatal care use: implications for maternal health care utilization in Ghana. Health Economics Review, 2(14), pp.1-8.

Bloom, S. S., Lippeveld, T., \& Wypij, D. (1999). Does antenatal care make a difference to safe delivery? A study in urban Uttar Pradesh, India. Health Policy and Planning, 14(1), pp.38-48.

Caldwell, J. (1979). Education as a factor in mortality decline: An examination of Nigerian data. Population Studies, 33(3), pp. 395413.

Chan, K., \& Kean, L. (2004). Routine antenatal management at the booking clinic. Current Obstetrics \& Gynaecology, 14, 79-85.

Govindasamy, P., \& Ramesh, B. (1997). Maternal education and utilization of maternal and child health services in India: NFHS Survey Subject Report No. 5. Mumbai: International Institute for Population Sciences.

Hobcarft, J. (1993). Women's education, child welfare and child survival:A review of the evidence. Retrieved Jan. 2, 2019, from Jstor: http:/ www.jstor.org/stable/40652016

Jejeebhoy, S. (1995). Women's education,autonomy, and reproductive behaviour: Experience from developing countries. Oxford University Press.

Kabir, M. R. (2016). Effect of women education on the utilization of antenatal care services in Banglades: A multivariable analysis of socioeconomic and emogragphic factors. Academia Journal of Education Research, 4(6), pp. 95-103.

Klemetti, R., Gissler, M., Sainio, S., \& Hemminki, E. (2013). Association of maternal age with maternity care use and birth outcomes in primiparous women: A comparision of result in 1991 and 2008 in Finland. Roal College of Obstetric and Gyneacologists, pp.356362.

Maternal Health Task Force. (n.d.). Retrieved Sepet. 22, 2018, from MHTF: https://www.mhtf.org/topics/antenatal-care/

McAlister, C., \& Baskett, T. F. (2006). Female education and maternal mortality: Aworldwide survey. J Obstet Gynaecol Can, 28(11), 983-90. 
McKinlay, J. B. (1972). Some approaches and problem in the study of the use of services-an overview. Journal of Health and Social Behaviour, 13(2), 115-152.

Ministry of Health, N., ERA, N., \& ICF. (2017). Nepal Demographic and Health Survey 2016. Kathmandu: Authors.

Ndidi, E., \& Oserement, I. G. (2010). Reasons given by pregnant women for late initiation of antenatal care in the Niger Delta, Nigeria. Ghana Medical Journal, 44(2), pp.47-51.

Pandy, K. K., \& Singh, R. (2015). Importance of socio-demographic factors on utilization of maternal health care services in India. Journal of Statistics Applications and Probability, 4(3), pp. 447-457.

Preda, A., \& Vogit, K. (2015). The social determinants of health:Why should we care? The American Journal of Bioethics, 15(3), pp. 25-36.

World Health Ogranization. (2009). Women and health-today's evidence tomorrow's agenda. Geneva: Author.

- - (2016). WHO recommendations on antenatal care for a positive pregnancy experiences. Geneva: Author.

World Health Organization; United Nations Children's Fund. (2003). Antenatal care in developing countries-promises, achievements and missed opportunities. Geneva: Author.

Yakong, V. N., Rush, K. L., Bassett-Smith, J., Bottorff, J. L., \& Ronison, C. (2010). Women's experiences of seeking reproductive health care in rural Ghana: Challenges for maternal health service utilization. Journal of Advanced Nursing, pp. 2431-2441.

Yakubovich, I. S., \& Barell, V. (1988). Maternal education as modifier of the association between low birthweight and infant mortality. International Journal of Epidemology, 17(2), pp. 370-377.

Zahr, A., \& Lidia, C. (2003). Antenatal care in developing countries: Promises, achievements and missed opportunities: An analysis of trend, levels and differntials, 1991-2001. Geneva: World Health Organization. 